\title{
Multifocal intraocular lenses and retinal diseases
}

\author{
Andrzej Grzybowski ${ }^{1,2}$ (D) Piotr Kanclerz ${ }^{3} \cdot$ Raimo Tuuminen $^{4,5}$
}

Received: 11 August 2019 / Revised: 4 January 2020 / Accepted: 8 January 2020/Published online: 18 January 2020

(C) The Author(s) 2020

\begin{abstract}
Purpose Multifocal intraocular lenses (MIOLs) are often discouraged in patients with or at risk of retinal disorders (including diabetic retinopathy, age-related macular degeneration, and epiretinal membranes), as MIOLs are believed to reduce contrast sensitivity (CS). Concerns with MIOLs have also been raised in individuals with visual field defects, fixation instability or eccentric preferred retinal locations. The aim of this study is to review the influence of MIOL on quality of vision in patients with retinal diseases.

Methods We reviewed the PubMed and Web of Science databases to identify relevant studies using the following keywords: multifocal intraocular lens, cataract surgery, cataract extraction, lens exchange, diabetic retinopathy, age-related macular degeneration, and contrast sensitivity.

Results Studies evaluating CS in MIOLs present conflicting results: MIOLs either did not influence CS or resulted in worse performance under low-illuminance conditions and higher spatial frequencies when compared to monofocal IOLs. Nevertheless, MIOLs preserved CS levels within the age-matched normal range. Two studies reported that patients with concurrent retinal diseases receiving a MIOL, both unilaterally and bilaterally, reported a significant improvement in visual-related outcomes. Individuals with a monofocal IOL in one eye and a MIOL in the fellow eye reported greater subjective satisfaction with the MIOL.

Conclusion We were unable to find evidence suggesting that patients with retinal diseases should be advised against MIOLs. Nevertheless, more research is needed to address the aforementioned concerns and to optimize the use of MIOLs in eyes with retinal disease.
\end{abstract}

Keywords Age-related maculardegeneration $\cdot$ Cataract surgery $\cdot$ Contrast sensitivity $\cdot$ Diabetic retinopathy $\cdot$ Multifocal intraocular lens $\cdot$ Refractive lens exchange

Electronic supplementary material The online version of this article (https://doi.org/10.1007/s00417-020-04603-0) contains supplementary material, which is available to authorized users.

Andrzej Grzybowski

ae.grzybowski@gmail.com

1 Department of Ophthalmology, University of Warmia and Mazury, Olsztyn, Poland

2 Institute for Research in Ophthalmology, Foundation for Ophthalmology Development, Poznan, Poland

3 Hygeia Clinic, Gdańsk, Poland

4 Helsinki Retina Research Group, Faculty of Medicine, University of Helsinki, Helsinki, Finland

5 Department of Ophthalmology, Kymenlaakso Central Hospital, Kotka, Finland

\section{Introduction}

Advances in cataract surgery and refractive lens exchange have enabled these techniques to be used to achieve precise and desired refractive outcomes[1]. This has raised patients' expectations of excellent uncorrected distance visual acuity[2]. However, with monofocal intraocular lenses (IOLs), the desire for freedom from spectacles cannot be completely met. Multifocal intraocular lenses (MIOLs) are used more commonly and to a considerable extent for refractive purposes in non-cataractous eyes [3]. It is believed that as MIOLs decrease contrast sensitivity, so they are advised against in patients with retinal disorders.

MIOLs utilize diffractive or refractive optics in order to produce two or more foci. A diffractive MIOL generates multifocality based on light interference. It incorporates a pattern consisting of a series of annular concentric grooves less than 1 micron in depth, which are engraved around the optical axis on either the front or the back surface of a lens (the echelette technology). With the refractive design, multifocality is achieved with light refraction on the MIOL surfaces based on Snell's law. 
The performance of refractive design MIOLs depends on pupil size and MIOL centration.

The increasing popularity of MIOLs underlines the importance of reviewing scientific evidence regarding their suitability in patients with ocular comorbidities to aid preoperative assessment and proper patient selection in MIOL candidates. The aim of this study is to review the influence of MIOL on quality of vision in patients with retinal diseases.

\section{Materials and methods}

The PubMed and Web of Science databases were the main resources used to investigate the medical literature. An extensive search was performed to identify relevant articles concerning "multifocal intraocular lenses" and "retinal diseases" up to June 30, 2018 (Appendix 1). The following keywords were used in various combinations: multifocal intraocular lens, cataract surgery, cataract extraction, lens exchange, diabetic retinopathy, age-related macular degeneration, and contrast sensitivity. The search identified 247 unique articles. Of the studies retrieved by this method, we reviewed all publications in English and abstracts of non-English publications. The reference lists of the articles analyzed were also considered as a potential source of information. We attempted to present all publications that employed MIOLs for patients with retinal diseases. Studies were critically reviewed to create an overview and guidance for further research. No attempts were made to discover unpublished data. In addition to the PubMed and Web of Science searches, selected chapters from relevant textbooks were included.

\section{Results}

\section{Contrast sensitivity (CS) and age}

Various procedures and systems are employed to evaluate contrast sensitivity. The results of these evaluations be affected by differences in methodology, including light conditions, speed of performing the test, or decision-making criteria. In 1978, Arden and Jacobson claimed that contrast sensitivity is independent of age, and since then, several studies have sought an association between contrast sensitivity and age [4]. Studies analyzing the relationship between CS and age are presented in Table 1. It might be concluded that contrast sensitivity decreases with age and that the greatest decrease is observed at higher spatial frequencies. Age and cataract are independently associated with this decline, and posterior subcapsular cataract affects CS in the highest degree. Lower CS was also reported in females and in Chinese, when compared to other races present in Singapore $[5,6]$. Moreover, CS at higher spatial frequencies is lower in myopes compared to emmetropes [5].
Burton et al. [12] suggested that optical rather than neural changes in the visual system contribute to loss of spatial contrast sensitivity at a photopic level in the elderly. This small loss in CS was presumably due to interaction of a laser speckle effect and increased light scattering in the aged eye. On the other hand, Elliot et al. [27] reported that the decrease in contrast sensitivity is due to neural loss. In their study, senile miosis and reduced optical transmission, which are believed to influence CS, were mimicked in younger subjects by reducing retinal illumination and did not result in a decrease in CS. Higgins et al. [17] believe that the high-spatial frequency decline in CS, although it is comparatively small, is too large to be due to changes in lens density related to age. This was confirmed by Owsley et al. [23], who demonstrated that after cataract surgery, elderly patients still have decreased CS at higher frequencies, although they have a crystalline IOL. The decline in visual performance might also be due to spatial integration and difficulty in processing visual information in the presence of noise [28]. Morrison and Jay [29] confirmed with laser interferometry that the optical functions with aging remain unchanged, while neural function significantly declines.

\section{CS and MIOLs}

Studies analyzing CS in MIOLs present conflicting results, as seen in Table 2. Comparing CS outcomes is difficult due to the differences in the tests used and different illumination levels and inconsistencies in the variables reported. One might conclude that CS with MIOLs was lower than with monofocal IOLs in at least some conditions; in some studies, MIOLs performed worse under low-illuminance conditions and at higher spatial frequencies. The outcome regarding CS might depend on the MIOL model and design: diffractive optics influence CS to a lesser degree [30]. However, the quality of evidence is poor. Furthermore, none of the studies presented an association between CS and the quality of vision [31]. CS improved with time and achieved an age normal range of 3-12 months after surgery. Similar results were presented in the meta-analysis by Rosen et al. [32] and in the review by Wang et al. [33]. Thus, doubts remain as to which MIOL design would offer the best visual performance and patient satisfaction in patients with retinal disease.

\section{Discussion}

\section{Contraindications for MIOLs}

Several doubts and contraindications for MIOL implantation currently exist. These include corneal aberrations, particularly coma or cone, which might result in a decreased contrast sensitivity and dysphotopsia. IOL decentration relative to the pupil center leads to an increase in high-order aberrations and diminished objective contrast discrimination. Thus, an asymmetric capsulorrhexis, 
Table 1 Studies analyzing the relationship between contrast sensitivity and age in a general population

\begin{tabular}{|c|c|c|}
\hline Study & Subjects (age) & Parameter analyzed \\
\hline $\begin{array}{l}\text { Karatepe et al. } \\
\quad 2017 \text { [7] }\end{array}$ & 37 individuals (aged 7-65 years) & $\begin{array}{l}\mathrm{CS} \text { at } 0.5,1.5,3.0, \\
6.0,12.0, \text { and } 24.0 \mathrm{cpd} \text { at } \\
\quad \text { illumination levels } \\
\text { of } 0-30 \mathrm{~dB}(\mathrm{~dB})\end{array}$ \\
\hline Sia et al. 2013 & 472 adults aged $35-80$ years & $\mathrm{CS}$ at $3,6,12$, and $18 \mathrm{cp}$ \\
\hline
\end{tabular}

Results

[8]

Hohberger et al. 61 subjects (categorized in age groups 2007 [9] $<30$ years, $30-39$ years, $40-49$ years, $50-59$ years, $>60$ years)

Nomura et al. 2003 [10]

Nio et al. $2000 \quad 100$ subjects (20-69 years of age [11]

Klein et al. 19965926 individuals (43-84 years of age) [6]

Burton et al.

Nameda et al. 1989 [13]

Tulunay-Keesey 63 adults (13-67 years of age) et al. 1988

[14]

Crassini et al. $1988[15]$

Sloane et al. $1988[16]$ $1993[12]$
35 young (aged $17-29$ years) and 29 older (aged $60-80$ years) subjects

19 individuals (aged $24-63$ years) frequencies of $0,1,5$, and $15 \mathrm{~Hz}$

CS (central an 10 deg temporally) at Young observers had better contrast sensitivities $0.2,0.8,2.0$, and $5.0 \mathrm{cpd}$

$$
\text { elderly (average age } 64.4 \text { years) }
$$

8 young (average age 20.4 years) and 8 subjects

\section{2 young (19-35 years) and 11 older} (68-89 years) subjects

CS at 2, 4, 8, 12, 16, 20, 24, 28, and Older adults in good eye health exhibited on $32 \mathrm{cpd}$ contrast sensitivity across the spatial frequency range tested

CS at 1.5, 2, 3, 4, 5, 6, 7, 8, 9, 10, 15, Losses at high spatial frequencies up to 40 years $20,30,40,50,60$, and $70 \mathrm{cpd} \quad$ of age. After 40 years of age, there were losses at all spatial frequencies

CS at spatial frequencies of $0.5,1,2$, Sensitivity for low spatial frequencies modulated at 0 to $15 \mathrm{~Hz}$ was not affected by age, but a progressive age-related elevation of threshold was found for combinations of high spatial and temporal frequencies

$$
\text { than older observers but }
$$

only at higher spatial frequencies (2.0 and $5.0 \mathrm{cpd}$ )

$\mathrm{CS}$ as a function of target luminance at $0.5,2,4$, and $8 \mathrm{cpd}$

When gratings were flickered at $0.5 \mathrm{~Hz}$, functions for older adults were displaced downward on
CS at $1.5,3,6,12$, and $18 \mathrm{cpd}$, under Contrast sensitivity was significantly reduced day $\left(85 \mathrm{~cd} / \mathrm{m}^{2}\right)$ and night $\left(3.0 \mathrm{~cd} / \mathrm{m}^{2}\right)$ conditions, with and without glare

CS at $1.5,3,6,12$, and $18 \mathrm{cpd}$

CS at $1,2,4,8$, and $16 \mathrm{cpd}$; pupil size 2,4 , and $6 \mathrm{~mm}$; defocus -1 to $+2 \mathrm{D}$

$\mathrm{CS}$ measured with a perimeter in the $25^{\circ}$ central field average a small loss $(0.1-0.2 \log$ unit) in

$\mathrm{CS}$ at nine spatial frequencies from 0.75 to $16 \mathrm{cpd}$

CS at $1,2,4,10.6$, and $16.5 \mathrm{cpd}$

Elliot 1987 [18] $\quad 16$ young (mean age $21.5+2.7$ years)

Yates et al. 1987103 adults (21-40 years of age) and 16 older (mean age $72 \pm 4.3$ years) subjects

50 subjects in five age groups (20-29, $30-39,40-49,50-59,60-69$ years)

1988 [17]$$
\text { (21-40 years of age) }
$$

$\mathrm{CS}$ the sensitivity axis across all luminance levels, and the slopes of these functions were steeper than those for younger adults, suggesting that optical mechanisms alone cannot account for the vision loss in older adults.

Decline in sensitivity with age at all spatial frequencies

Lower contrast sensitivity at medium (4 cpd) and high $(10.6,16.5 \mathrm{cpd})$ spatial frequencies in older group

The age-related decrease in CS was found only at $16 \mathrm{cpd}$ 
Table 1 (continued)

\begin{tabular}{|c|c|c|c|}
\hline Study & Subjects (age) & Parameter analyzed & Results \\
\hline $\begin{array}{l}\text { Ross et al. } 1985 \\
\quad[20]\end{array}$ & $\begin{array}{l}17 \text { young (aged } 20-30 \text { years) and } 53 \\
\text { older (aged 50-87 years) subjects }\end{array}$ & $\begin{array}{l}\mathrm{CS} \text { at } 0.4,0.95,2.88,6.73,12.70 \\
\text { and } 19.23 \mathrm{cpd}\end{array}$ & $\begin{array}{l}\text { Lower performance in older group compared to } \\
\text { younger group at all spatial frequencies In the } \\
\text { older group, linear decline in CS with age for } \\
\text { medium and high spatial frequencies }\end{array}$ \\
\hline $\begin{array}{l}\text { Morrison and } \\
\text { McGrath } \\
1985[21]\end{array}$ & 45 observers (including 4 elderly) & $\begin{array}{l}\text { CS } 8-40 \mathrm{cpd}(10-15 \text { different } \\
\text { frequencies within this range) }\end{array}$ & $\begin{array}{l}\text { With increasing age, CS remained steady until the } \\
\text { sixth decade when they declined }\end{array}$ \\
\hline $\begin{array}{l}\text { Kline et al. } 1983 \\
\text { [22] }\end{array}$ & $\begin{array}{l}16 \text { young }(18-25 \text { years }) \text { and } 16 \text { old } \\
(55-70 \text { years }) \text { subjects }\end{array}$ & $\mathrm{CS}$ at $0.5,2,4,6,8$, and $12 \mathrm{cpd}$ & $\begin{array}{l}\text { An age-related loss in contrast sensitivity was } \\
\text { observed primarily for stimuli of intermediate } \\
\text { and high spatial frequency }\end{array}$ \\
\hline $\begin{array}{c}\text { Owsley et al. } \\
1983 \text { [23] }\end{array}$ & 91 adults aged $19-87$ years & $\mathrm{CS}$ at $0.5,1,2,4,8$, and $16 \mathrm{cpd}$ & $\begin{array}{l}\text { At higher spatial frequencies. Sensitivity } \\
\text { decreased with age around } 40 \text { to } 50 \text { years }\end{array}$ \\
\hline $\begin{array}{l}\text { McGrath and } \\
\text { Morrison } \\
1981[24]\end{array}$ & 66 subjects (5-94 years old) & $\mathrm{CS}$ at $1,2,3,5,10,20$, and $25 \mathrm{cpd}$ & $\begin{array}{l}\text { With advancing age, there was an overall decrease } \\
\text { in contrast sensitivity. The loss of CS was } \\
\text { greater for middle range spatial frequencies } \\
\text { than for higher spatial frequencies }\end{array}$ \\
\hline $\begin{array}{c}\text { Sekuler et al. } \\
1980[25]\end{array}$ & $\begin{array}{l}25 \text { young (mean age } 18.5 \pm 0.7 \text { years) } \\
\text { and } 10 \text { old }(73.2+3.8 \text { years }) \\
\text { individuals }\end{array}$ & $\begin{array}{l}\mathrm{CS} \text { at } 0.5,1,2,4,8 \text {, and } 16 \mathrm{cps} \\
\text { flickered at } 0.3 \text { or } 6 \mathrm{~Hz}\end{array}$ & $\begin{array}{l}\text { Older and younger observers did not differ in } \\
\text { ability to see targets with fine structure (high } \\
\text { spatial frequencies); older observers were only } \\
\text { one-third as sensitive to targets with coarse } \\
\text { structure (low spatial frequencies) as were } \\
\text { younger observers. Older observers were also } \\
\text { less able than younger observers to see moving } \\
\text { targets }\end{array}$ \\
\hline $\begin{array}{l}\text { Derefeldt et al. } \\
1979 \text { [26] }\end{array}$ & $\begin{array}{l}10 \text { children (aged } 6-10 \text { years), } 12 \text { adults } \\
\text { (aged } 20-40 \text { years), } 5 \text { adults (aged } \\
40-60 \text { years), } 11 \text { adults (aged } 60 \text { years } \\
\text { or older) }\end{array}$ & $\begin{array}{l}\mathrm{CS} \text { at } 0.5,1.0,2.0,4.0,10,20 \text {, and } \\
\quad 40 \mathrm{cpd}\end{array}$ & $\begin{array}{l}\text { No significant difference between young- and } \\
\text { middle-aged subjects with regard to contrast } \\
\text { sensitivity. For higher ages studied (above } \\
60 \text { years), there was a loss of sensitivity in the } \\
\text { middle and high frequency regions }\end{array}$ \\
\hline $\begin{array}{l}\text { Arden \& } \\
\quad \text { Jacobson } \\
1978[4]\end{array}$ & $\begin{array}{l}50 \text { healthy adults aged } 17-64 \text { years, } 7 \\
\text { eyes with ocular hypertension, } 43 \text { eyes } \\
\text { with glaucoma }\end{array}$ & $\mathrm{CS}$ at $0.4,0.8,1.6,3.2$, and $6.4 \mathrm{cpd}$ & $\begin{array}{l}\text { The variation in the test results with age in } \\
\text { normals is only slight. }\end{array}$ \\
\hline
\end{tabular}

cpd cycles per degree, $C S$ contrast sensitivity

haptics deformation, or finally IOL subluxation might disqualify a patient from an MIOL. As the IOL pseudoexfoliation syndrome is correlated with zonular instability, centration in these patients is questionable. Patients with a large pupil, postoperative ametropia, and astigmatism or who have developed posterior capsule opacification are at risk of dissatisfaction after MIOL implantation [59, 60]. Multifocals are strictly disadvised in retinitis pigmentosa and Stargardt's disease, while diabetic retinopathy, age-related macular degeneration, and epiretinal membranes are relative contraindications [61]. In light of this, a thoughtful approach would be recommended in patients with neuro-ophthalmological conditions (e.g., strabismus, Horner's syndrome) or glaucomatous visual field defects [62, 63].

\section{Evidence on MIOLs and retinal diseases}

Only two studies assessed the visual outcome of MIOLs in patients with concurrent retinal diseases (Table 3). Kamath et al. [64] reported that patients with concurrent eye diseases including age-related macular degeneration, glaucoma, or diabetic retinopathy benefited from the multifocality of an IOL. The MIOL arm of the study comprised 81 eyes (70 patients) and the monofocal arm 52 eyes (41 patients). Distance visual acuities were similar in the monofocal IOL and MIOL groups, while uncorrected near visual acuity (UNVA) was significantly better in the MIOL group. Patients who had a monofocal IOL in one eye and a MIOL (Array, Abbott Medical Optics Santa Ana, CA) in the fellow eye reported greater subjective satisfaction with the MIOL; however, 3 of these 11 patients had more advanced pathology in the eye with the monofocal IOL, making it difficult to interpret the significance of this finding. However, no clear definition of "more advanced pathology" was given by the authors. Our study demonstrated that the results are divergent, even when they only include normal eyes without concurrent retinal diseases. Nevertheless, one might question whether the presence of eye diseases should be a decisive reason to categorically advise against MIOLs.

Gayton et al. [65] proposed implantation of Acrysof Restor (Alcon, Fort Worth, TX) targeting -2.0D in eyes with agerelated macular degeneration and corrected distance visual 
Table 2 Contrast sensitivity in multifocal intraocular lenses

\begin{tabular}{lll}
\hline Study & IOLs (number of eyes) & Parameter analyzed
\end{tabular}

$\begin{array}{cc}\text { Altermir-Gomez } & \text { Tecnis ZCB00 (AMO, } n=44) \text { vs. Tecnis } \\ \text { et al. } 2019 & \text { ZMB00 (AMO, } n=78)\end{array}$

[34]

Menucci et al. PanOptix IQ (Alcon, $n=40$ ), AT LISA tri 2018 [35] 839MP (Carl Zeiss Meditec, $n=40)$, Tecnis Symfony (AMO, $n=40)$

Dyrda et al. 2018 OptiVis (Aaren Scientific, $n=64$ ) vs. AR40E CS at 1.5, 3, 6, 12, and $18 \mathrm{cpd}$ [36] (AMO, $n=64$ ) vs. M-Flex (Rayner, $n=64$ ) vs. ReZoom (AMO, $n=64)$ vs. ReSTOR (Alcon, $n=64$ )

Pedrotti et al. $2018[30]$

Tecnis (AMO, $n=30)$, vs. Tecnis Symfony (AMO, $n=55$ ), vs. ReSTOR +2.5 (Alcon, $n=50$ ), vs. ReSTOR +3.0 (Alcon, $n=50$ )

otti et al. 2018 [37]

Maxwell et al. 2017 [38]

Plaza-Puche et al. 2016 [39]

Labiris et al. 2015 [40]

Gil et al. 2014 [41]

Tan et al. 2014 [42]

Yamauchi et al. 2013 [43]

Comfort LS-313 MF 15 (Lentis, $n=11$ ) vs. monofocal Tecnis (AMO, $n=12$ )

Monofocal Acrysof SN60WF (Alcon) vs. Acrysof IQ Restor +2.5

AT LISA tri 839MP (Carl Zeiss Meditec, $n=30$ ), FineVision (Physiol, $n=30$ ), MPlus-LS313 (Lentis, $n=30$ ), AcriLisa 366D (Carl Zeiss Meditec, $n=30$ ), ReSTOP SN6AD1 (Alcon, $n=30$ ), monofocal spherical Acri.Smart 48S (Carl Zeiss Meditec, $n=30$ )

multifocal Isert PY60MV (Hoya, $n=37$ ) vs. monovision SN60WF (Alcon, $n=38$ )

Acrysof ReSTOR SN6AD1 (Alcon, $n=35$ ) vs. Acrysof ReSTOR SN60D3 (Alcon, $n=36)$ vs. Tecnis ZMA00 (AMO, $n=38$ ) vs. ReZoom NXG (AMO, $n=33$ ) vs. Tecnis ZA9003 (AMO, $n=38$ )

Ji et al. 2013 [44] monofocal Acrysof Natural (Alcon, $n=27$ ) vs. Acrysof ReSTOR (Alcon, $n=24$ )

Wilkins et al 2013 [45]

Zhao et al. 2010 [46]

Martínez Palmer et al. 2008 [47]

Tecnis ZM900 (AMO, $n=106)$ vs. monovision Akreos AO (Bausch \& Lomb, $n=105$ )

kreos AO (Bausch \& Lomb) vs. ZMA00 $n=128$ eyes)

Tecnis ZA9003/ZCB00 (AMO) vs. ZMA00/ZMB00 (AMO)

Acrysof ReSTOR SA60D3 (Alcon, $n=72$ ) v Acrysof SA60AT (Alcon, $n=89$ )

Tecnis Z9000 (AMO, $n=48)$ vs. Tecnis ZM900 (AMO, $n=52$ ) vs. ReZoom (AMO, $n=64$ ) vs. TwinSet (AcriTec, $n=64$ ) and photopic)
CS at 6,12 , and $18 \mathrm{cpd}\left(85 \mathrm{~cd} / \mathrm{m}^{2}\right.$ at $4 \mathrm{~m}$ )

CS at 3, 6, 12, and $18 \mathrm{cpd}$

CS at $1.5,3,6,12$, and $18 \mathrm{cpd}$ (mesopic and photopic)

$\mathrm{CS}$ at $3,6,12$, and $18 \mathrm{cpd}$ (photopic); mesopic 1.5, 3.0, 6.0, and $12.0 \mathrm{cpd}$ with and without glare

CS at 1.5, 3, 6, 12, and $18 \mathrm{cpd}$ in low mesopic levels

CS with Pelli-Robson chart

distance CS at 3, 6, 12, and $18 \mathrm{cpd}$ (8 levels of contrast), near CS at $1.5,3,6,12$, and $18 \mathrm{cpd}$ (8 levels of contrast)

CS visual acuity was measured at contrast levels: $100 \%, 25 \%$, $10 \%$, and $5 \%$

CS with optotype size $0.7,1,1.6$, $2.5,4$, and 6.3 degree with and without glare

$\mathrm{CS}$ at $0.7,1.0,1.6,2.5,4.0$, and $6.3 \mathrm{cpd}$; scotopic $\left(80 \mathrm{~cd} / \mathrm{m}^{2}\right)$ and mesopic $\left(5 \mathrm{~cd} / \mathrm{m}^{2}\right)$ conditions

CS with Pelli-Robson chart

$\mathrm{CS}$ at $1.5,3,6,12$, and $18 \mathrm{cpd}$

$\mathrm{CS}$ at $1.5,3,6,12$, and $18 \mathrm{cpd}$ in mesopic and scotopic conditions, with and without glare

$\mathrm{CS}$ at $1.5,3,6,12$, and $18 \mathrm{cpd}$

CS at 3, 6, 12, and $18 \mathrm{cpd}$ (mesopic No difference in CS

The Tecnis Symfony MIOLs provided significantly better photopic and mesopic CS outcomes than the other MIOL models

Only under mesopic conditions without glare, distance CS with the MIOL was significantly lower than with the monofocal IOL at any tested frequencies

No differences in photopic CS between the monofocal IOL and the EDOF Tecnis Symfony in any spatial frequency. In contrast, all contrast sensitivity values for these two lenses were significantly better than those obtained with both apodized diffractive refractive ReSTOR MIOLs

no differences in CS

No relevant differences in binocular CS under photopic or mesopic conditions, with or without glare

No differences in CS in low mesopic conditions at $1.5,3,6$, and $12 \mathrm{cpd}$ but only at $18 \mathrm{cpd}$. In pair comparison found better values for monofocal than ReSTOR at $18 \mathrm{cpd}$

\section{No differences in CS}

Monofocal better at all spatial frequencies Diffractive optics and aspheric profiles showed a non-statistically significant trend to perform better in mesopic conditions. Near CS was lower for refractive, distance dominant lens designs, particularly at medium to high spatial frequencies

No significant differences of the CS visual acuity were present among the three groups at 3 months after surgery

CS (with and without glare) was better in the monofocal group

Monofocal presented better CS at all spatial frequencies and conditions

Monovision better than multifocal $(p=0.009)$

Better CS at $3 \mathrm{cpd}$ in monofocal IOL

Mean contrast sensitivity was better for the monofocal IOL group than for the MIOLs. Patients assigned to TwinSet had less favorable contrast sensitivity scores compared to newer design multifocals

All groups behaved similarly. At $3 \mathrm{cpd}$, the monofocal IOL (AR40) and diffractive 
Table 2 (continued)

\begin{tabular}{|c|c|c|c|}
\hline Study & IOLs (number of eyes) & Parameter analyzed & Results \\
\hline & $\begin{array}{l}\text { AR40 (AMO, } n=15) \text { vs. Array SA40N } \\
\quad(\mathrm{AMO}, n=16) \text { vs. ReZoom }(\mathrm{AMO}, n=15) \\
\text { vs. ZM900 }(n=16)\end{array}$ & & $\begin{array}{l}\text { pupil-independent MIOL (ZM900) groups } \\
\text { exhibited a higher sensitivity than the } \\
\text { refractive MIOL groups (ReZoom and } \\
\text { ZM900) }(P=0.038)\end{array}$ \\
\hline $\begin{array}{l}\text { Harman et al. } \\
2008[49]\end{array}$ & $\begin{array}{c}1 \mathrm{CU}(n=28) \text { vs. Array SA } 40 \mathrm{~N}(\mathrm{AMO}, \\
n=27) \text { vs. Clariflex }(\mathrm{AMO}, \mathrm{n}=27)\end{array}$ & CS with Pelli-Robson chart & $\begin{array}{l}\text { CS slightly higher in } 1 \mathrm{CU} \text { than in array at } \\
3 \text { months, No differences at } 18 \text { months }\end{array}$ \\
\hline $\begin{array}{l}\text { Zeng et al. } 2007 \\
\quad[50]\end{array}$ & $\begin{array}{l}\text { Z9001 (AMO, } n=40) \text { vs. SA60AT (Alcon, } \\
\quad n=45) \text { vs. SA40N (AMO, } n=39)\end{array}$ & $\begin{array}{l}\mathrm{CS} \text { at } 6,12 \text {, and } 18 \mathrm{cpd}\left(85 \mathrm{~cd} / \mathrm{m}^{2}\right. \\
\text { at } 4 \mathrm{~m}) \text { with and without glare }\end{array}$ & $\begin{array}{l}\text { Z9001 showed better CS than SA40AT, while } \\
\text { SA60AT better than SA40N (significant at } \\
\text { all spatial frequencies) }\end{array}$ \\
\hline $\begin{array}{l}\text { Sen et al. } 2004 \\
\quad[51]\end{array}$ & $\begin{array}{l}\text { SI-40NB (AMO, } n=67) \text { vs. Array SA- } 40 \mathrm{~N} \\
\quad(\mathrm{AMO}, n=53)\end{array}$ & $\mathrm{CS}$ at $1.5,3,6,12$, and $18 \mathrm{cpd}$ & $\begin{array}{l}\text { CS was slightly lower with MIOLs at all } \\
\text { spatial frequencies; the difference was not } \\
\text { significant and decreased over time }\end{array}$ \\
\hline $\begin{array}{l}\text { Montés-Micó } \\
\text { et al. } 2004 \\
\text { [52] }\end{array}$ & $\begin{array}{l}\text { SI- } 40 \mathrm{NB}(\mathrm{AMO}, n=32) \text { vs. Array SA- } 40 \mathrm{~N} \\
\quad(\mathrm{AMO}, n=32)\end{array}$ & $\mathrm{CS}$ at $1.5,3,6,12$, and $18 \mathrm{cpd}$ & $\begin{array}{l}\text { As low luminances, distance CS for MIOL } \\
\text { worse than monofocal IOL for highest } \\
\text { spatial frequencies ( } 12 \text { and } 18 \mathrm{cpd}) \text {. Under } \\
\text { bright conditions no difference - CS within } \\
\text { normal limits }\end{array}$ \\
\hline $\begin{array}{l}\text { Leyland et al. } \\
2002[53]\end{array}$ & $\begin{array}{l}\text { S140 N (AMO) vs. Array SA40NB (AMO) } \\
\text { vs. TrueVista 68STUV (Storz) }\end{array}$ & CS with Pelli-Robson chart at $1 \mathrm{~m}$ & $\begin{array}{l}\text { Mean binocular contrast } \\
\text { sensitivity was } 1.74 \text { (SD } 0.15) \text { for the } \\
\text { monofocal IOL, } 1.67(0.13) \text { for the } \\
\text { multifocal, and } 1.65(0.20) \text { for the bifocal } \\
\text { (unclear in statistically significant) }\end{array}$ \\
\hline $\begin{array}{l}\text { Kamlesh et al. } \\
\text { 2001 [54] }\end{array}$ & $\begin{array}{l}\text { Progres } 3 \text { (Domilens, } n=20 \text { ) vs. Flex } 65 \\
\quad \text { (Domilens, } n=20 \text { ) }\end{array}$ & $\begin{array}{l}\text { CS with Pelli-Robson chart at } \\
\quad 90 \mathrm{~cd} / \mathrm{m}^{2}\end{array}$ & $\begin{array}{l}\text { Mean CS was lower in patients with MIOLs } \\
\text { than those with a monofocal IOL }(1.38 \text { vs. } \\
1.56 \log \text { units; } p<0.001)\end{array}$ \\
\hline $\begin{array}{l}\text { Haaskjold et al. } \\
1998[55]\end{array}$ & $\begin{array}{l}\text { Diffractive bifocal PMMA 808X (Pharmacia, } \\
\begin{array}{l}n=115 \text { ) vs. monofocal } 808 \mathrm{D} \text { (Pharmacia, } \\
n=106 \text { ) }\end{array}\end{array}$ & $\begin{array}{l}\mathrm{CS} \text { at } 1.5,3,6,12 \text {, and } 18 \mathrm{cpd} \text { at } \\
\text { distance and near }\end{array}$ & $\begin{array}{l}\text { Bifocal had lower CS than monofocal IOL at } \\
\text { all spatial frequencies }\end{array}$ \\
\hline $\begin{array}{l}\text { Allen et al. } 1996 \\
\text { [56] }\end{array}$ & $\begin{array}{l}\text { Diffractive bifocal PMMA 808X (Pharmacia, } \\
\begin{array}{l}n=79 \text { ) vs. monofocal } 808 \mathrm{D} \text { (Pharmacia, } \\
n=70 \text { ) }\end{array}\end{array}$ & $\begin{array}{l}\mathrm{CS} \text { at } 1.5,3,6,12 \text {, and } 18 \mathrm{cpd} \text { at } \\
\text { three light levels }\end{array}$ & $\begin{array}{l}\text { Differences in CS at all light levels. } \\
\text { Particularly in medium light, bifocal group } \\
\text { had reduced CS compared with monofocal } \\
\text { IOL but still within normal limits }\end{array}$ \\
\hline $\begin{array}{c}\text { Percival et al. } \\
1993[57]\end{array}$ & PC25 (AMO, $n=25)$ vs. Array (AMO, $n=25)$ & Regan system & $\begin{array}{l}\text { Slightly lower CS in MIOLs than monofocal } \\
\text { IOLs at all contrast levels, not statistically } \\
\text { significant }\end{array}$ \\
\hline $\begin{array}{l}\text { Steinert et al. } \\
1992[58]\end{array}$ & $\begin{array}{l}\text { PC- } 25 \mathrm{NB}(\mathrm{AMO}, n=30) \text { vs. Array } \\
\quad \mathrm{MPC}-25 \mathrm{NB}(\mathrm{AMO}, n=32)\end{array}$ & Regan system & $\begin{array}{l}\text { MIOL worse than monofocal IOL only at } 11 \% \\
\text { contrast level }\end{array}$ \\
\hline
\end{tabular}

$C S$ contrast sensitivity, $I O L$ intraocular lens, $M I O L$ multifocal intraocular lens

acuity (CDVA) of 20/50 or worse. This approach is particularly interesting as it provided an uncorrected near + 5.2D addition. The CDVA improved in 14 out of 20 eyes (70\%) and the UNVA in 18 out of 20 (90\%) eyes. Particularly for patients receiving MIOLs, evaluation of vision-related quality of life shoud be considered [66]. Within this study patients

Table 3 Studies assessed visual outcomes of MIOL implantation in patients with concurrent retinal diseases

\begin{tabular}{llll}
\hline Study & IOL & Diseases & Conclusion \\
\hline Gayton et al. [63] & $\begin{array}{c}\text { Acrysof Restor } \\
\text { targeting -2.0D (Alcon) }\end{array}$ & $\begin{array}{c}\text { Dry age-related macular degeneration } \\
\text { or macular degeneration associated } \\
\text { with disciform scarring. }\end{array}$ & $\begin{array}{c}\text { In cataractous eyes with age-related macular } \\
\text { degeneration, replacing the crystalline lens } \\
\text { with this myopia-targeted multifocal } \\
\text { intraocular lens improved or maintained } \\
\text { near vision without severely compromising } \\
\text { distance vision }\end{array}$ \\
Kamath et al. [62] & $\begin{array}{c}\text { Multifocal array (AMO) vs. } \\
\text { monofocal SI-40NB0 (AMO) }\end{array}$ & $\begin{array}{c}\text { Age-related macular degeneration } \\
\text { Glaucoma Ocular Hypertension } \\
\text { Diabetic Retinopathy Others }\end{array}$ & $\begin{array}{c}\text { The IOLs presented similar distance visual } \\
\text { outcomes; however, a proportion of patients } \\
\text { benefited from the IOLs' multifocality }\end{array}$ \\
\hline
\end{tabular}


reported a significant improvement in visual-related items of the 25-item Visual Function Questionnaire (VFQ-25) in both unilateral and bilateral MIOL groups. It was concluded that such an approach provided an improvement in near vision that is not available with standard cataract surgery.

\section{Uncertainty about the future}

Progression of a macular disease after cataract and refractive lens exchange is a problematic issue [59], as patients might develop macular diseases years after the primary surgery. Thus, it might be questioned whether a MIOL should be disadvised in a diabetic patient who is at risk of developing macular edema or should we advise against MIOLs only in patients with a present macular edema or in all diabetics? There is no evidence that MIOLs should be disadvised in these patients.

One doubt that remains is what levels of CS should be considered as normal, given its large standard deviation in healthy subjects? Whether MIOL should be compared with age-matched phakic or pseudophakic monofocal IOL subjects? What level of reduction in CS should be considered as clinically significant? And finally, what is the threshold in CS to contraindicate MIOLs?

\section{Conclusions}

We were unable to find evidence suggesting that patients with macular diseases should be advised against MIOLs. Several contraindications for MIOLs in patients with retinal diseases have a hypothetical character and are not evidence-based. More research is needed especially to address the effect of MIOLs on CS, visual functions, and patient activities such as orientation, mobility, and reading in various retinal pathologies.

\section{Compliance with ethical standards}

Conflict of interest Dr. Grzybowski reports non-financial support from Bayer, non-financial support from Novartis, non-financial support from Alcon, personal fees and non-financial support from Valeant, grants from Zeiss, personal fees and non-financial support from Santen, outside the submitted work. Dr. Kanclerz reports non-financial support from Visim and Optopol Technology. Dr. Tuuminen reports non-financial support from Bayer, personal fees from Novartis, personal fees from Alcon, personal fees from Allergan, non-financial support from Thea, outside the submitted work.

Ethical approval This article does not contain any studies with human participants performed by any of the authors.

Open Access This article is licensed under a Creative Commons Attribution 4.0 International License, which permits use, sharing, adaptation, distribution and reproduction in any medium or format, as long as you give appropriate credit to the original author(s) and the source, provide a link to the Creative Commons licence, and indicate if changes were made. The images or other third party material in this article are included in the article's Creative Commons licence, unless indicated otherwise in a credit line to the material. If material is not included in the article's Creative Commons licence and your intended use is not permitted by statutory regulation or exceeds the permitted use, you will need to obtain permission directly from the copyright holder. To view a copy of this licence, visit http://creativecommons.org/licenses/by/4.0/.

\section{References}

1. Grzybowski A, Kanclerz P (2019) Recent developments in cataract surgery. Current Concepts in Opthalmology 55-97. https://doi.org/ 10.1007/978-3-030-25389-9 3

2. Grzybowski A, Kanclerz P (2019) Do we need day-1 postoperative follow-up after cataract surgery? Graefe's Archive for Clinical and Expiremental Opthalmology 257(5):855-61

3. European Registry of Quality Outcomes for Cataract and Refractive Surgery. http://www.eurequo.org/. Accessed 13 Feb 2019

4. Arden GB, Jacobson JJ (1978) A simple grating test for contrast sensitivity: preliminary results indicate value in screening for glaucoma. Invest Ophthalmol Vis Sci 17:23-32

5. Oen FT, Lim TH, Chung MP (1994) Contrast sensitivity in a large adult population. Ann Acad Med Singap 23:322-326

6. Klein BE, Klein R, Jensen SC (1996) Visual sensitivity and agerelated eye diseases. The beaver dam eye study. Ophthalmic Epidemiol 3:47-55

7. Karatepe AS, Köse S, Eğrilmez S (2017) Factors affecting contrast sensitivity in healthy individuals: a pilot study. Turk J Ophthalmol 47:80-84

8. Sia DIT, Martin S, Wittert G, Casson RJ (2013) Age-related change in contrast sensitivity among Australian male adults: Florey adult male ageing study. Acta Ophthalmol 91:312-317

9. Hohberger B, Laemmer R, Adler W et al (2007) Measuring contrast sensitivity in normal subjects with OPTEC 6500: influence of age and glare. Graefes Arch Clin Exp Ophthalmol 245:1805-1814

10. Nomura H, Ando F, Niino $\mathrm{N}$ et al (2003) Age-related change in contrast sensitivity among Japanese adults. Jpn J Ophthalmol 47: 299-303

11. Nio YK, Jansonius NM, Fidler V et al (2000) Age-related changes of defocus-specific contrast sensitivity in healthy subjects. Ophthalmic Physiol Opt 20:323-334

12. Burton KB, Owsley C, Sloane ME (1993) Aging and neural spatial contrast sensitivity: photopic vision. Vis Res 33:939-946

13. Nameda N, Kawara T, Ohzu H (1989) Human visual spatiotemporal frequency performance as a function of age. Optom Vis Sci 66:760-765

14. Tulunay-Keesey U, Ver Hoeve JN, Terkla-McGrane C (1988) Threshold and suprathreshold spatiotemporal response throughout adulthood. J Opt Soc Am A 5:2191-2200

15. Crassini B, Brown B, Bowman K (1988) Age-related changes in contrast sensitivity in central and peripheral retina. Perception 17:315-332

16. Sloane ME, Owsley C, Jackson CA (1988) Aging and luminanceadaptation effects on spatial contrast sensitivity. J Opt Soc Am A 5: 2181-2190

17. Higgins KE, Jaffe MJ, Caruso RC, deMonasterio FM (1988) Spatial contrast sensitivity: effects of age, test-retest, and psychophysical method. J Opt Soc Am 5:2173-2180

18. Elliott DB (1987) Contrast sensitivity decline with ageing: a neural or optical phenomenon? Ophthalmic Physiol Opt 7:415-419

19. Yates JT, Terry Yates J, Harrison JM et al (1987) Contrast sensitivity. Optom Vis Sci 64:519-527

20. Ross JE, Clarke DD, Bron AJ (1985) Effect of age on contrast sensitivity function: uniocular and binocular findings. $\mathrm{Br} \mathrm{J}$ Ophthalmol 69:51-56 
21. Morrison JD, McGrath C (1985) Assessment of the optical contributions to the age-related deterioration in vision. Q J Exp Physiol 70:249-269

22. Kline DW, Schieber F, Abusamra LC, Coyne AC (1983) Age, the eye, and the visual channels: contrast sensitivity and response speed. J Gerontol 38:211-216

23. Owsley C, Sekuler R, Siemsen D (1983) Contrast sensitivity throughout adulthood. Vis Res 23:689-699

24. McGrath C, Morrison JD (1981) The effects of age on spatial frequency perception in human subjects. Q J Exp Physiol 66:253-261

25. Sekuler R, Hutman LP, Owsley CJ (1980) Human aging and spatial vision. Science 209:1255-1256

26. Derefeldt G, Lennerstrand G, Lundh B (1979) Age variations in normal human contrast sensitivity. Acta Ophthalmol 57:679-690

27. Elliott D, Whitaker D, MacVeigh D (1990) Neural contribution to spatiotemporal contrast sensitivity decline in healthy ageing eyes. Vis Res 30:541-547

28. Andersen GJ (2012) Aging and vision: changes in function and performance from optics to perception. Wiley Interdiscip Rev Cogn Sci 3:403-410

29. Morrison JD, Jay JL (1993) Changes in visual function with normal ageing, cataract and intraocular lenses. Eye 7(Pt 1):20-25

30. Pedrotti E, Carones F, Aiello F et al (2018) Comparative analysis of visual outcomes with 4 intraocular lenses: monofocal, multifocal, and extended range of vision. J Cataract Refract Surg 44:156-167

31. Grzybowski A, Kanclerz P, Muzyka-Woźniak M (2019) Methods for evaluating quality of life and vision in patients undergoing lens refractive surgery. Graefes Arch Clin Exp Ophthalmol 257:1091-1099

32. Rosen E, Alió JL, Dick HB et al (2016) Efficacy and safety of multifocal intraocular lenses following cataract and refractive lens exchange: metaanalysis of peer-reviewed publications. J Cataract Refract Surg 42:310-328

33. Wang SY, Stem MS, Oren G et al (2017) Patient-centered and visual quality outcomes of premium cataract surgery: a systematic review. Eur J Ophthalmol 27:387-401

34. Altemir-Gomez I, Millan MS, Vega F, et al (2019) Comparison of visual and optical quality of monofocal versus multifocal intraocular lenses. Eur J Ophthalmol 1120672119827858

35. Mencucci R, Favuzza E, Caporossi O et al (2018) Comparative analysis of visual outcomes, reading skills, contrast sensitivity, and patient satisfaction with two models of trifocal diffractive intraocular lenses and an extended range of vision intraocular lens. Graefes Arch Clin Exp Ophthalmol 256:1913-1922

36. Dyrda A, Martínez-Palmer A, Martín-Moral D et al (2018) Clinical results of diffractive, refractive, hybrid multifocal, and monofocal intraocular lenses. J Ophthalmol 2018:8285637

37. Pedrotti E, Mastropasqua R, Bonetto J et al (2018) Quality of vision, patient satisfaction and long-term visual function after bilateral implantation of a low addition multifocal intraocular lens. Int Ophthalmol 38:1709-1716

38. Maxwell A, Holland E, Cibik L et al (2017) Clinical and patientreported outcomes of bilateral implantation of a 2.5 diopter multifocal intraocular lens. J Cataract Refract Surg 43:29-41

39. Plaza-Puche AB, Alio JL, Sala E, Mojzis P (2016) Impact of low mesopic contrast sensitivity outcomes in different types of modern multifocal intraocular lenses. Eur J Ophthalmol 26:612-617

40. Labiris G, Giarmoukakis A, Patsiamanidi M et al (2015) Minimonovision versus multifocal intraocular lens implantation. $\mathrm{J}$ Cataract Refract Surg 41:53-57

41. Gil MA, Varón C, Cardona G et al (2014) Comparison of far and near contrast sensitivity in patients symmetrically implanted with multifocal and monofocal IOLs. Eur J Ophthalmol 24:44-52

42. Tan N, Zheng D, Ye J (2014) Comparison of visual performance after implantation of 3 types of intraocular lenses: accommodative, multifocal, and monofocal. Eur J Ophthalmol 24:693-698
43. Yamauchi T, Tabuchi H, Takase K et al (2013) Comparison of visual performance of multifocal intraocular lenses with same material monofocal intraocular lenses. PLoS One 8:e68236

44. Ji J, Huang X, Fan X, Luo M (2013) Visual performance of Acrysof ReSTOR compared with a monofocal intraocular lens following implantation in cataract surgery. Exp Ther Med 5:277-281

45. Wilkins MR, Allan BD, Rubin GS et al (2013) Randomized trial of multifocal intraocular lenses versus monovision after bilateral cataract surgery. Ophthalmology 120:2449-2455.e1

46. Zhao G, Zhang J, Zhou Y et al (2010) Visual function after monocular implantation of apodized diffractive multifocal or single-piece monofocal intraocular lens. J Cataract Refract Surg 36:282-285

47. Martínez Palmer A, Gómez Faiña P, España Albelda A et al (2008) Visual function with bilateral implantation of monofocal and multifocal intraocular lenses: a prospective, randomized, controlled clinical trial. J Refract Surg 24:257-264

48. Cillino S, Casuccio A, Di Pace F et al (2008) One-year outcomes with new-generation multifocal intraocular lenses. Ophthalmology 115:1508-1516

49. Harman FE, Maling S, Kampougeris G et al (2008) Comparing the $1 \mathrm{CU}$ accommodative, multifocal, and monofocal intraocular lenses: a randomized trial. Ophthalmology 115:993-1001.e2

50. Zeng M, Liu Y, Liu X et al (2007) Aberration and contrast sensitivity comparison of aspherical and monofocal and multifocal intraocular lens eyes. Clin Exp Ophthalmol 35:355-360

51. Sen HN, Sarikkola A-U, Uusitalo RJ, Laatikainen L (2004) Quality of vision after AMO array multifocal intraocular lens implantation. J Cataract Refract Surg 30:2483-2493

52. Montés-Micó R, España E, Bueno I et al (2004) Visual performance with multifocal intraocular lenses: mesopic contrast sensitivity under distance and near conditions. Ophthalmology 111:85-96

53. Leyland MD, Langan L, Goolfee F et al (2002) Prospective randomised double-masked trial of bilateral multifocal, bifocal or monofocal intraocular lenses. Eye 16:481-490

54. Kamlesh DS, Kaushik S (2001) Contrast sensitivity and depth of focus with aspheric multifocal versus conventional monofocal intraocular lens. Can J Ophthalmol 36:197-201

55. Haaskjold E, Allen ED, Burton RL et al (1998) Contrast sensitivity after implantation of diffractive bifocal and monofocal intraocular lenses. J Cataract Refract Surg 24:653-658

56. Allen ED, Burton RL, Webber SK et al (1996) Comparison of a diffractive bifocal and a monofocal intraocular lens. J Cataract Refract Surg 22:446-451

57. Percival SPB, Setty SS (1993) Prospectively randomized trial comparing the pseudoaccommodation of the AMO ARRAY multifocal lens and a monofocal lens. J Cataract Refract Surg 19:26-31

58. Steinert RF, Post CT Jr, Brint SF et al (1992) A prospective, randomized, double-masked comparison of a zonal-progressive multifocal intraocular lens and a monofocal intraocular lens. Ophthalmology 99:853-861

59. Braga-Mele R, Chang D, Dewey S et al (2014) Multifocal intraocular lenses: relative indications and contraindications for implantation. J Cataract Refract Surg 40:313-322

60. de Vries NE, Webers CAB, Touwslager WRH et al (2011) Dissatisfaction after implantation of multifocal intraocular lenses. J Cataract Refract Surg 37:859-865

61. Alio JL, Plaza-Puche AB, Férnandez-Buenaga R et al (2017) Multifocal intraocular lenses: an overview. Surv Ophthalmol 62:611-634

62. Aychoua N, Junoy Montolio FG, Jansonius NM (2013) Influence of multifocal intraocular lenses on standard automated perimetry test results. JAMA Ophthalmol 131:481-485

63. Prakash G, Prakash DR, Agarwal A et al (2011) Predictive factor and kappa angle analysis for visual satisfactions in patients with multifocal IOL implantation. Eye 25:1187-1193 
64. Kamath GG, Prasad S, Danson A, Phillips RP (2000) Visual outcome with the array multifocal intraocular lens in patients with concurrent eye disease. J Cataract Refract Surg 26:576-581

65. Gayton JL, Mackool RJ, Ernest PH et al (2012) Implantation of multifocal intraocular lenses using a magnification strategy in cataractous eyes with age-related macular degeneration. J Cataract Refract Surg 38:415-418
66. Grzybowski A, Kanclerz P, Muzyka-Woźniak M (2019) Methods for evaluating quality of life and vision in patients undergoing lens refractive surgery. Graefe's Archive for Clinical and Experimental Ophthalmology 257:1091-99

Publisher's note Springer Nature remains neutral with regard to jurisdictional claims in published maps and institutional affiliations. 